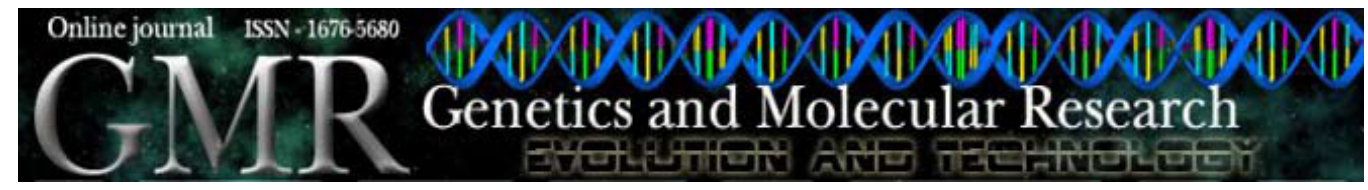

\title{
Meiotic behavior and karyotypic variation in Acledra (Pentatomidae, Heteroptera)
}

\author{
P.J. Rebagliati and L.M. Mola
}

Departamento de Ecología Genética y Evolución, Laboratorio de Citogenética y Evolución, Facultad de Ciencias Exactas y Naturales, Universidad de Buenos Aires, Ciudad Autónoma de Buenos Aires, Argentina

Corresponding author: P.J. Rebagliati

E-mail: gchu@ege.fcen.uba.ar

Genet. Mol. Res. 9 (2): 739-749 (2010)

Received January 10, 2010

Accepted February 20, 2010

Published April 20, 2010

DOI 10.4238/vol9-2gmr763

\begin{abstract}
Acledra comprises 15 taxonomically identified species, most of which are crop pests. This is the first cytogenetic study of species of this genus. Acledra kinbergii and A. modesta showed the modal number of the Pentatomidae $(2 \mathrm{n}=14=12+$ $\mathrm{XY})$, while $A$. bonariensis had a reduced complement $(2 \mathrm{n}=12=$ $10+\mathrm{XY})$, with a markedly larger autosomal pair. Meiotic behavior follows the general pattern of the family; the autosomes divide pre-reductionally, the sex chromosomes are achiasmatic and divide post-reductionally, and at metaphase II the autosomes show a ring-shaped configuration with the pseudobivalent at the center. However, the configuration at metaphase I varies; $A$. modesta shows the typical arrangement (ring of bivalents with the sex chro-
\end{abstract}


mosomes lying at its center). In A. kinbergii, the sex chromosomes are part of the ring or only the Y chromosome is at the center. In $A$. bonariensis, the ring arrangement is not well defined. There are also differences at the diffuse stage; chromatin strands of different width are observed in $A$. bonariensis and $A$. modesta, whereas bivalents do not entirely lose their identity in $A$. kinbergii. In $A$. bonariensis, the reduced complement may have originated from the fusion of the two larger non-homologous autosomes, which could characterize the ancestral karyotype of this genus. The presence of secondary constrictions in the larger pair of $A$. modesta and $A$. bonariensis may support this hypothesis. Since secondary constrictions are uncommon in the holokinetic chromosomes of heteropterans, their presence in these species may indicate that it is a plesiomorphic character of the genus.

Key words: Meiosis; Karyotypic variation; Holokinetic chromosomes; Acledra; Pentatomidae; Heteroptera

\section{INTRODUCTION}

The Pentatomidae are one of the most important families of the suborder Heteroptera, not only in view of the large number of taxonomically described species (more than 4100 species) but also because they include major pests of economically important crops (Schaefer and Panizzi, 2000). In particular, most of the 15 taxonomically identified species of the genus Acledra Signoret, 1864 (subfamily Pentatominae, tribe Carpocorini) are pests of such crops as soybean, bean, carrot, and flax (Schaefer and Panizzi, 2000; Di Iorio, 2004; Rider, 2008).

About 300 species of this family have been cytogenetically analyzed; the diploid number ranges between 6 and 27 although in males, the numbers 12, 14 and 16 are present in approximately $95 \%$ of the species; with a common mode of 14 chromosomes (83\% of the species). The predominant sex chromosome-determining system is $\mathrm{XY} / \mathrm{XX}$; the $\mathrm{X}_{1} \mathrm{X}_{2} \mathrm{Y} /$ $\mathrm{X}_{1} \mathrm{X}_{1} \mathrm{X}_{2} \mathrm{X}_{2}$ system is found in two species, Thyanta calceata and Macropygium reticulare, and the neo-XY system only in Rhytidolomia senilis (Ueshima, 1979; Papeschi et al., 2003; Kerzhner et al., 2004; Rebagliati et al., 2001, 2005; Lanzone and Souza, 2006; Souza et al., 2007, 2008; Rebagliati, 2009). This family has holokinetic chromosomes, as is the case for all heteropterans.

In regard to meiotic development, a diffuse post-pachytene stage is often observed at prophase I. At metaphase I, autosomal bivalents (usually with a chiasma) arrange in a ring-shaped figure with the sex chromosomes lying side-by-side at its center. The first meiotic division is reductional for the autosomes and equational for the sex chromosomes. At metaphase II, the autosomes are once more arranged in a ring configuration, but the sex chromosomes associate achiasmatically forming a pseudobivalent located at the center of the autosomal ring. The second meiotic division is equational for the autosomes and reductional for the sex chromosomes (Ueshima, 1979; Manna, 1984; Suja et al., 2000; Rebagliati et al., 2001; Lanzone and Souza, 2006; Mola and Papeschi, 2006). 
In the present study, the characteristics of meiotic development of three species of the genus Acledra: A. kinbergii, A. modesta and A. bonariensis are described and compared for the first time. The frequency and distribution of chiasmata were analyzed in these species, and the distribution and composition of the heterochromatin were determined for $A$. kinbergii using 4'-6-diamidino-2-phenylindole-chromomycin $\mathrm{A}_{3}\left(\mathrm{DAPI}^{\left.-\mathrm{CMA}_{3}\right)}\right.$ ) banding. A discussion of the mechanisms of karyotype evolution involved in the variation of the chromosome number is provided.

\section{MATERIAL AND METHODS}

The material analyzed comprised adult males of Acledra kinbergii from Gualeguaychú (Province of Entre Ríos, Argentina) (3 males) and Sierra de la Ventana (Province of Buenos Aires) (1 male), A. modesta from Los Reartes (Province of Córdoba) (3 males), and $A$. bonariensis from Martín García Island (Province of Buenos Aires) (1 male).

The specimens were fixed in absolute ethanol:glacial acetic acid $(3: 1)$, and then dissected to remove the testes. For studies of meiotic behavior, preparations were performed by squashing a piece of gonad in propionic hematoxylin or using the method of Guerra (1999). In brief, a piece of gonad is first hydrolyzed in $5 \mathrm{~N} \mathrm{HCl}$, stained with $1 \%$ alum hematoxylin and finally squashed in $45 \%$ acetic acid. Fluorescent staining with $\mathrm{CMA}_{3}$ and DAPI was carried out on unstained slides. A piece of gonad was squashed in $45 \%$ acetic acid; the coverslip was then removed by the dry-ice method, and the slide was air-dried. The sequential DAPI-CMA 3 banding was performed using the technique described by Rebagliati et al. (2003).

\section{RESULTS}

Acledra kinbergii has $\mathrm{n}=6+\mathrm{XY}$. Positively heteropycnotic sex chromosomes, usually lying together, are seen during early meiotic prophase (Figure 1a, b). After pachytene, at the diffuse stage, cells increase in size and bivalents become partially decondensed without completely losing their identity; this substage is herein referred to as diffuse diplotene. At this substage, one or two nucleoli of different size are associated with small positive heteropycnotic blocks in the telomeric regions of the second bivalent (Figure 1b). From diakinesis onward, there are two larger bivalents of different size, three medium-sized bivalents of similar size and one small bivalent; the size of the $\mathrm{X}$ chromosome is similar to that of the small bivalent, and the Y-chromosome is about half the size of the $\mathrm{X}$ chromosome (Figure 1c-e). At metaphase I, the sex chromosomes are usually part of the bivalent ring ( $82.93 \%$ of 41 cells analyzed) (Figure 1d), or only the $\mathrm{Y}$ chromosome is at its center (17.07\%) (Figure 1e). At anaphase I, the autosomal bivalents segregate reductionally and the sex chromosomes equationally (Figure 1f). At metaphase II, the XY pseudobivalent is localized at the center of the autosomal ring, where the sex chromosomes retain their typical close association or are slightly separated (Figure 1g). At anaphase II, the autosomes segregate synchronously with the sex chromosomes (Figure $1 \mathrm{~h}$ ); the autosomes segregate equationally and the XY pseudobivalent reductionally, giving rise to two types of telophase II: one with six autosomes and the $\mathrm{X}$ chromosome, and the other one with six autosomes and the Y chromosome (Figure 1i). 


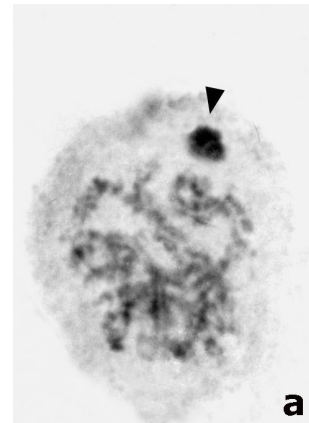

a

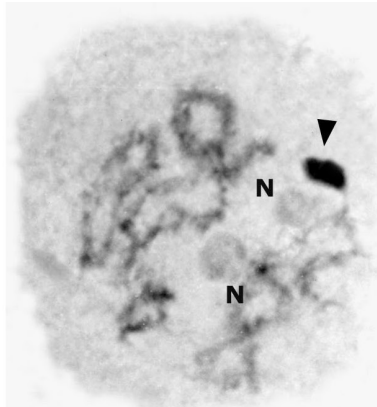

b

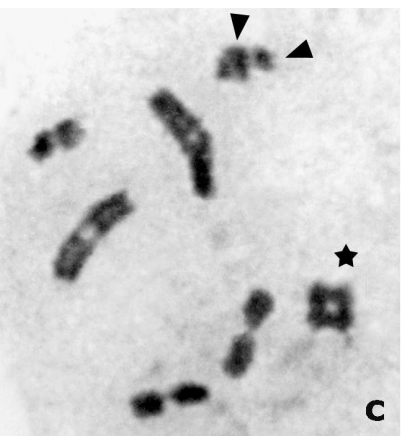

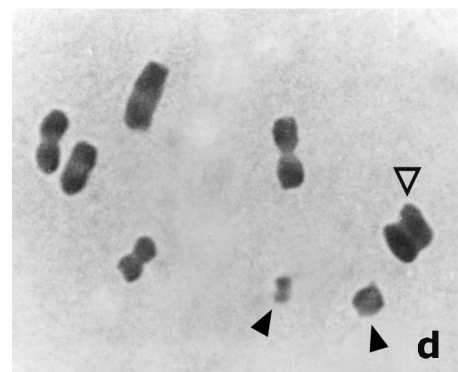

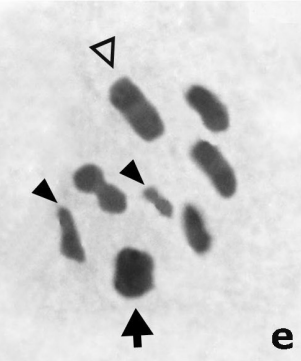

e
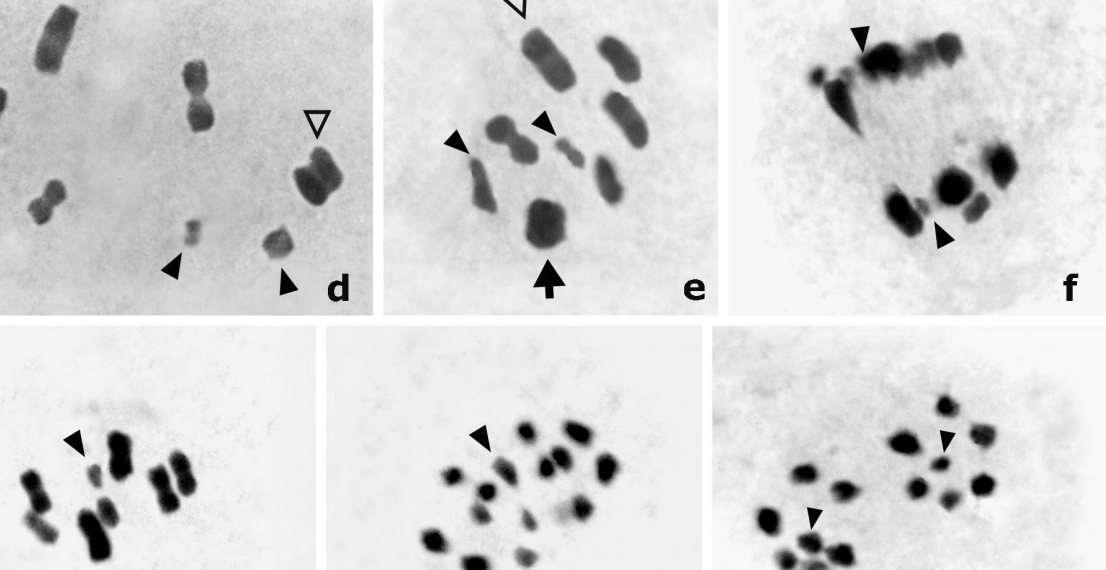

$\mathbf{g}$
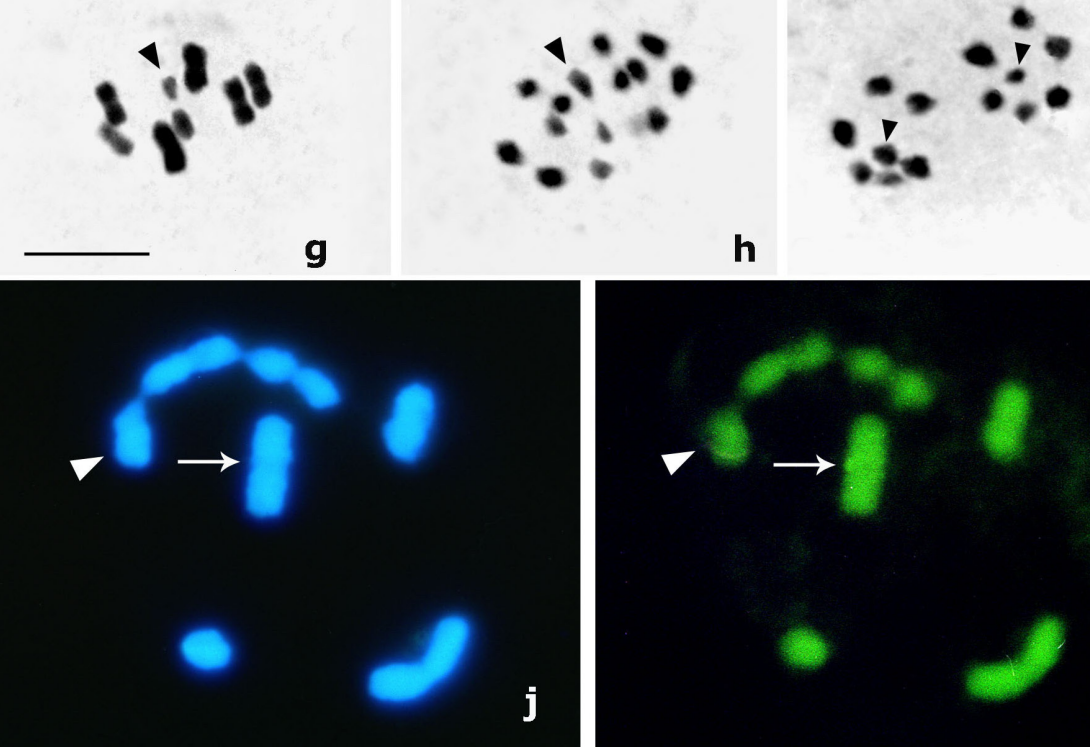

h

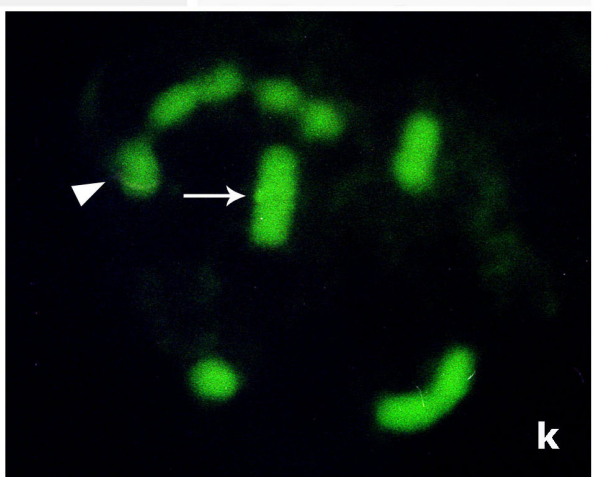

Figure 1. Acledra kinbergii, $\mathrm{n}=6+\mathrm{XY}$. a. Pachytene. b. Diffuse diplotene. c. Diakinesis. d.e. Metaphase I. f. Anaphase I. g. Metaphase II. h. Anaphase II. i. Telophase II. j.k. Diakinesis. Empty arrowheads point to the largest bivalent with one chiasma (d,e) or two chiasmata (d). Asterisk shows the medium-sized bivalent with an interstitial chiasma (c). Arrow shows the second bivalent with two chiasmata (e). White arrows (j,k) show DAPI dull-CMA bright band. Arrowheads point to the sex chromosomes. a-i) Conventional staining, j) DAPI staining, k) $\mathrm{CMA}_{3}$ staining. $\mathrm{N}=$ nucleolus. $\mathrm{Bar}=10 \mu \mathrm{m}$. 
The bivalents usually show a terminal chiasma, except for a few cells with an interstitial chiasma in one of the medium-sized bivalents (Figure 1c). In specimens from Gualeguaychú, the chiasma frequency analysis in cells at diakinesis-metaphase I shows a variable percentage of ring bivalents in the three specimens, with a mean chiasma frequency of $6.14,6.26$, and 6.34 (Table 1). A detailed analysis of chiasma distribution in specimen 1 indicates that in 44 cells having a single ring bivalent, it corresponds to the largest bivalent ( $88.64 \%$ of the cells), the second in size $(9.09 \%$ of the cells) or one of the middle-sized bivalents (in one cell, 2.27\%) (Figure 1d, e). In the only cell with eight chiasmata, the ring bivalents correspond to the larger bivalents. DAPI-CMA 3 banding shows that the sex chromosomes are DAPI-CMA 3 bright at prophase I. From diakinesis onward, all the bivalents are uniformly stained with DAPI-CMA ${ }_{3}$, except for the second in size, which shows a pair of DAPI dull-CMA ${ }_{3}$ bright telomeric bands. When this bivalent shows a chiasma, it is located in the banded telomeric region or in the opposite region in the same proportion (Figure $1 \mathrm{j}, \mathrm{k}$ ).

\begin{tabular}{|c|c|c|c|c|c|}
\hline Species & $\begin{array}{c}\text { Total number } \\
\text { of cells }\end{array}$ & $\begin{array}{c}\text { Mean chiasma } \\
\text { frequency }\end{array}$ & $\begin{array}{c}\% \text { of cells with } \\
6 \text { chiasmata }\end{array}$ & $\begin{array}{c}\% \text { of cells with } \\
7 \text { chiasmata }\end{array}$ & $\begin{array}{c}\% \text { of cells with } \\
8 \text { chiasmata }\end{array}$ \\
\hline \multicolumn{6}{|c|}{ A. kinbergii } \\
\hline 1 & 180 & 6.26 & 75.00 (135 c.) & 24.44 (44 c.) & $0.56(1 \mathrm{c})$. \\
\hline 2 & 205 & 6.34 & 66.34 (136 c.) & 33.66 (69 c.) & 0.00 \\
\hline 3 & 140 & 6.14 & $85.71(120 \mathrm{c})$. & $14.29(20 \mathrm{c})$. & 0.00 \\
\hline \multicolumn{6}{|c|}{ A. modesta } \\
\hline 1 & 40 & 6.225 & 77.50 (31 c.) & 22.50 (9 c.) & 0.00 \\
\hline
\end{tabular}

c. $=$ cells.

Acledra modesta has $\mathrm{n}=6+\mathrm{XY}$. During early prophase I, the sex univalents are positively heteropycnotic, lying together or separated (Figure 2a-c). During the diffuse postpachytene stage, the cell increases in size; the bivalents become decondensed until they lose identity forming chromatin strands of different width, and the sex chromosomes remain condensed (Figure 2c). No cells were observed at diplotene. Two larger bivalents of different size, three medium-sized bivalents of similar size and one bivalent slightly smaller are observed from diakinesis onward; the X-chromosome and the smaller bivalent are of comparable sizes and the Y-chromosome is the smallest of the complement (Figure 2f, g). The larger pair has a subterminal secondary constriction (Figure 2e-g). At metaphase I, the autosomal bivalents show a ring-shaped arrangement and the sex chromosomes are located at their center (Figure $2 \mathrm{~g}, \mathrm{~h}$ ). At anaphase I, the segregation is reductional for the autosomal bivalents and equational for the sex chromosomes, resulting in telophases I with eight chromosomes at each pole (six autosomes plus $\mathrm{X}$ and $\mathrm{Y}$ ) (Figure 2i, j). At metaphase II, the XY pseudobivalent is located within the autosomal ring (Figure $2 \mathrm{k}$ ), and at anaphase II, it segregates reductionally.

The bivalents usually have a terminal chiasma (Figure $2 \mathrm{f}-\mathrm{h}$ ) (Table 1). In one specimen, the analysis of chiasma distribution at diakinesis-metaphase I reveals that the largest bivalent or the second one in size (Figure 2d) may present two terminal chiasmata (77.78 and $22.22 \%$, respectively, of the total cells with ring bivalents) (Table 1). When the large bivalent shows a chiasma, it is often located in the telomeric region adjacent to the secondary constriction (Figure 2f, g). 


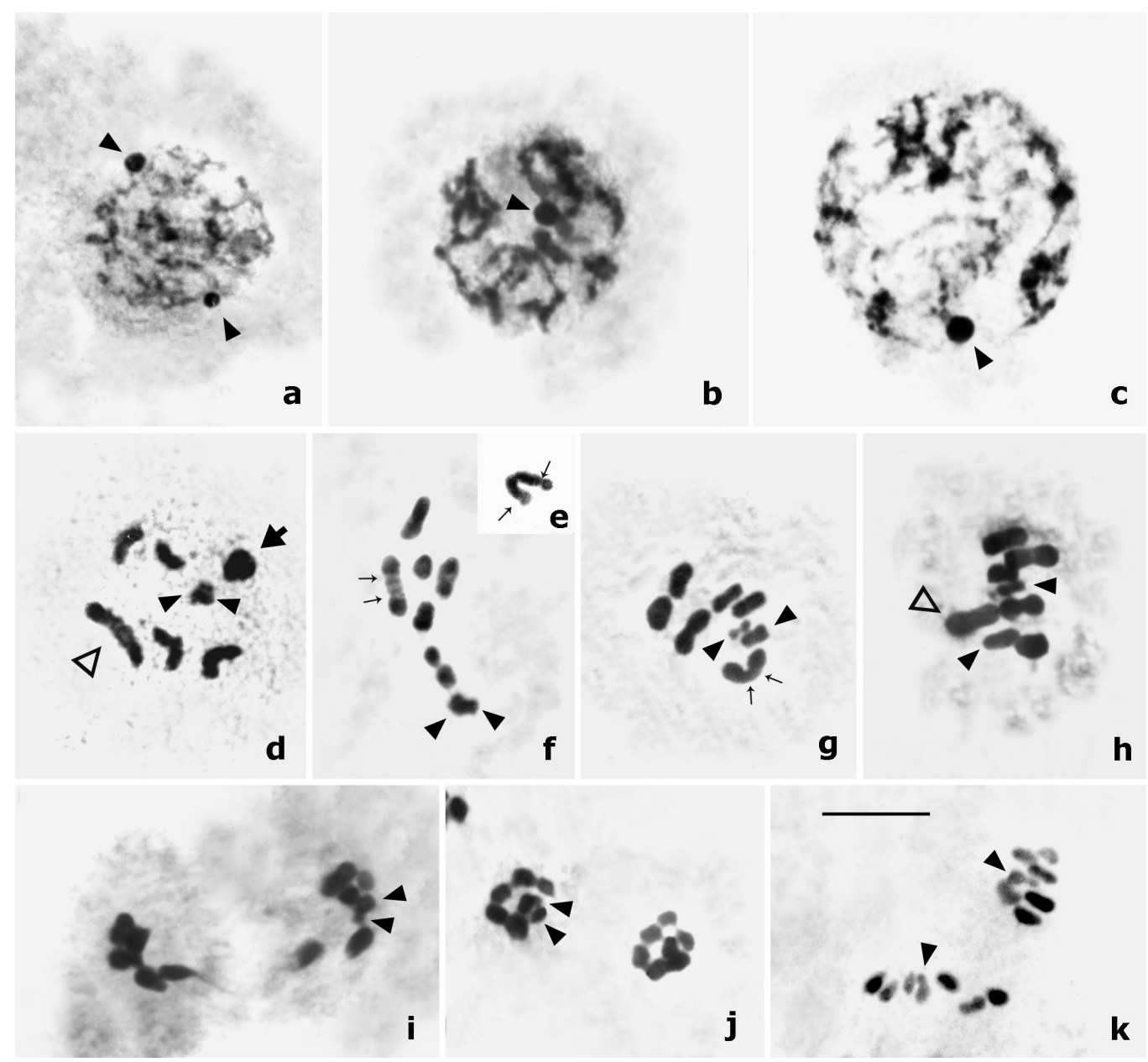

Figure 2. Acledra modesta, $\mathrm{n}=6+\mathrm{XY}$. a. Pachytene. b.c. Diffuse stage. d.f. Diakinesis. e. Detail of the largest bivalent. g.h. Metaphase I. i. Anaphase I. j. Telophase I. k. Metaphase II. Empty arrowheads point to the largest bivalent. Arrow shows the second bivalent with two chiasmata. Fine arrows point to the secondary constriction of the largest bivalent. Arrowheads point to the sex chromosomes. Bar $=10 \mu \mathrm{m}$.

Acledra bonariensis has $\mathrm{n}=5+\mathrm{XY}$. During the early meiotic prophase, the sex univalents are positively heteropycnotic, and are usually found together (Figure 3a). From pachytene onward, the cell undergoes a diffuse stage at which thin chromatin strands are observed; the sex chromosomes increase in size slightly and are less positively heteropycnotic (Figure $3 b$ ). At diplotene the sex chromosomes become isopycnotic (Figure 3c). A remarkably larger autosomal bivalent with a subterminal secondary constriction, three medium-sized bivalents decreasing gradually in size, and a smaller bivalent are observed from diakinesis onward; the $\mathrm{X}$ chromosome and the smaller bivalent are of comparable sizes, and the $\mathrm{Y}$ chromosome is the smallest of the complement (Figure 3d). At metaphase I, the largest bivalent often adopts 
the shape of a horizontal $\mathrm{V}$ and lies adjacent to the other bivalents and sex chromosomes. All these are not arranged in a well-defined ring figure; in only a few cells, the larger bivalent is located far from the rest of the chromosomes (Figure 3e). At anaphase I, the autosomes segregate reductionally and the sex chromosomes equationally. At metaphase II, the chromatids of the larger chromosome are generally almost associated along its major axis; this chromosome is part of the autosomal ring, and the pseudobivalent is located at its center (Figure 3f). At anaphase II, the autosomes divide equationally and the sex chromosomes reductionally. In the individual analyzed, at diakinesis, the larger bivalent has one or two terminal chiasmata (65 and $35 \%$, respectively, of 20 cells examined), whereas the rest of the bivalents always have only one (Figure $3 \mathrm{~d}$ ). No ring bivalents are seen at metaphase I.

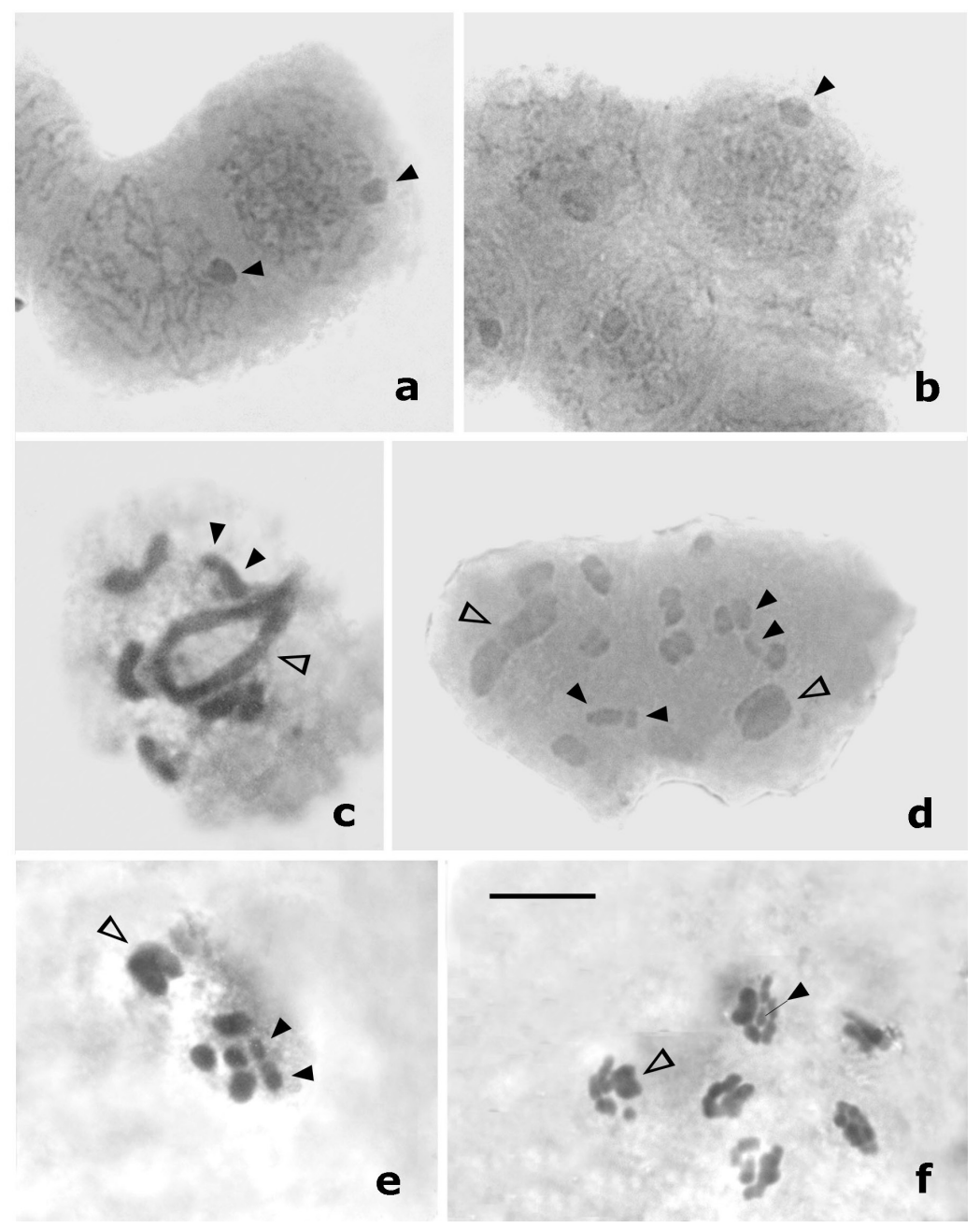

Figure 3. Acledra bonariensis, $\mathrm{n}=5+\mathrm{XY}$. a. Zygotene and Pachytene. b. Diffuse stage. c. Diplotene. d. Diakinesis. e. Metaphases I. f. Metaphases II. Empty arrowheads point to the larger pair. Arrowheads point to the sex chromosomes. Bar $=10 \mu \mathrm{m}$. 


\section{DISCUSSION}

The comparison of the meiotic behavior among three species of the genus Acledra revealed particular characteristics of the diffuse stage, chiasma frequency and the location of the autosomes and sex chromosomes at metaphase I.

The presence of a post-pachytene diffuse stage is frequent in Heteroptera, and its length and degree of bivalent decondensation vary between species (Solari, 1979; Rebagliati et al., 1998; Jacobs and Liebenberg, 2001; Bressa et al., 2002, 2003; Cattani and Papeschi, 2004; Cattani et al., 2004; Morielle-Souza and Azeredo-Oliveira, 2007; Bardella et al., 2008; Viera et al., 2009). Indeed, most of the pentatomid species in which meiosis was analyzed show a diffuse stage (Ueshima, 1979; Rebagliati et al., 2001, 2003; Lanzone and Souza, 2006; Souza et al., 2007; Viera et al., 2009). At the beginning of this stage, pachytene bivalents become less defined and the nucleus and the cell increase in size. As bivalents decondense, they lose their identity and chromatin strands can be distinguished; in some species autosomes decondense completely, and the nucleus looks like an interphase nucleous. The sex chromosomes remain condensed and appear positively heteropycnotic. Loose structures with a poorly defined border are distinguished at the beginning of chromosome recondensation, which coincide with the number of bivalents (diffuse diplotene). The length of the different substages of the diffuse stage and the extent to which the cell and nucleus increase in size vary among species.

This stage may be followed by a short diplotene and continues through a typical diakinesis. Chromatin decondensation is incomplete at the diffuse stage of $A$. bonariensis and $A$. modesta, with strands of different width. The chromatin of $A$. modesta shows a lower degree of decondensation and a very rapid subsequent recondensation, since no cells were seen at the diplotene stage. Instead, only a diffuse diplotene was detected in A. kinbergii. A. bonariensis differs from the other two species in that the sex chromosomes also decondense but to a lower degree than the autosomes. The diffuse stage, as demonstrated in the female meiosis, may also correspond to a phase of active synthesis in spermatocytes and pollen mother cells (Henderson, 1964; Klásterská, 1977; Benavente and Wettstein, 1980).

In the suborder Heteroptera, the bivalents usually show a terminal chiasma (Ueshima, 1979; Manna, 1984). However, the few existing detailed studies of chiasma frequency suggest that the presence of ring bivalents and interstitial chiasmata may be higher than previously thought (Mola and Papeschi, 1993; González-García et al., 1996; Bressa et al., 2002, 2003; Papeschi et al., 2003; Poggio et al., 2007). Studies in the Pentatomidae indicate the presence of one chiasma per bivalent; however, in Nezara viridula, Proxys albopunctatus, Dinocoris prolineatus, and Edessa rufomarginata, the larger bivalent may show two chismata with a variable frequency, whereas Loxa deducta and E. meditabunda have up to two ring bivalents (Camacho et al., 1985; Rebagliati et al., 2001, 2003; Papeschi et al., 2003). Antiteuchus mixtus and A. sepulcralis have no bivalents with two chiasmata but exhibit a variable frequency of subterminal and interstitial chiasmata (Lanzone and Souza, 2006). In the three species of Acledra analyzed in this study, the larger bivalent may have two chiasmata; the frequency of cells with this ring bivalent varies not only among species but also among individuals of $A$. kinbergii. In a smaller proportion of cells of $A$. modesta and $A$. kinbergii, the ring bivalent may correspond to the second in size and, uncommonly, to one of the medium-sized bivalents. Moreover, in A. kinbergii, a medium-sized bivalent may show an interstitial chiasma and both 
larger bivalents two chiasmata. Chiasma frequency analysis performed in a larger number of Pentatomidae species shows that one of the bivalents, most often the larger one, shows two chiasmata in a variable proportion of cells, suggesting that the presence of ring bivalents is common rather than exceptional.

Another characteristic of pentatomids is that at metaphase I bivalents form a ring with the sex chromosomes lying side-by-side at the center (Ueshima, 1979). This configuration occurs in $A$. modesta, whereas in $A$. kinbergii, the bivalent ring is also formed by the sex chromosomes in most of the cells, or only the Y-chromosome is located at its center. In $A$. bonariensis, the ring-shaped arrangement cannot be identified due to a reduction in chromosome number and the morphology and size of the larger bivalent. In the latter species, the larger bivalent frequently adopts the shape of a horizontal $\mathrm{V}$ at metaphase I. Taking into account that only $22.5 \%$ of the cells at diakinesis show two chiasmata, this arrangement may result from an asynchronous attachment to the spindle fibers due to their size, together with the release of one of the chiasmata to allow spindle attachment. This assumption has been proposed for the larger bivalent of Pachylis argentinus (Coreidae) and Largus rufipenis (Largidae) (Mola and Papeschi, 1993; Papeschi et al., 2003).

The association between GC-rich regions and nucleolar organizer regions (NORs) is frequent in Heteroptera (González-García et al., 1996; Rebagliati et al., 2003; Cattani et al., 2004; Bressa et al., 2005; Papeschi and Bressa, 2006; Severi-Aguiar et al., 2006). In A. kinbergii, GC-rich regions (DAPI dull-CMA bright) are located on one of the telomeric regions of the second pair and colocalize with the positively heteropycnotic blocks associated with the nucleolus, suggesting that they are NORs.

Although the NORs could not be characterized in A. modesta and A. bonariensis, they would be located on the subterminal secondary constrictions of the larger pair occurring in both species, as observed in P. argentinus (Coreidae) and N. viridula (Papeschi et al., 2003). On the other hand, secondary constriction non-coincident with NORs has been described in Belostoma oxyurum (Belostomatidae) and Spartocera fusca (Coreidae) (Papeschi and Bidau, 1985; Cattani and Papeschi, 2004); therefore, the location of NORs cannot be determined for these two Acledra species.

In the Pentatomidae, the reduction in diploid number through fusions of autosomes and/or sex chromosomes is less frequent than its increase through fragmentations of both autosomes and sex chromosomes ( $4 \mathrm{vs} 11 \%$ of the number of species cytogenetically analyzed) (Rebagliati et al., 2005). Acledra kinbergii and A. modesta have the modal number of the family $(\mathrm{n}=6+\mathrm{XY})$ and a similar karyotype. On the other hand, A. bonariensis shows a reduced complement $(\mathrm{n}=5+\mathrm{XY})$ with a markedly larger pair and shares with the other two species the three medium-sized pairs and the smaller pair. This chromosome complement may have originated from the fusion of two larger non-homologous autosomes, which could characterize the ancestral karyotype of the genus. The presence of secondary constrictions in the larger pair of A. modesta and A. bonariensis would support this hypothesis. Since secondary constrictions are uncommon in the holokinetic chromosomes of heteropterans, their occurrence in these two species may indicate that it is a plesiomorphic character of the genus (Colombo and Bidau, 1985; Papeschi and Bidau, 1985; Papeschi et al., 2003; Cattani and Papeschi, 2004).

Further cytogenetic studies in a larger number of Acledra species involving the characterization and location of the heterochromatic regions and NORs are needed to have a more in-depth understanding of the karyotypic evolution of this genus. 


\section{ACKNOWLEDGMENTS}

Research supported by grants from the Buenos Aires University (UBA) (X317, X178) and CONICET (PIP 5927, PIP 0342) awarded to Drs. L. Poggio (Director) and L.M. Mola (Co-Director). The authors wish to thank Dr. Jocelia Grazia from Departamento de Zoologia, Universidade Federal do Rio Grande do Sul, Porto Alegre, RS, Brazil, for taxonomic identification of the specimens included in the study.

\section{REFERENCES}

Bardella VB, Azeredo-Oliveira MT and Tartarotti E (2008). Cytogenetic analysis in the spermatogenesis of Triatoma melanosoma (Reduviidae; Heteroptera). Genet. Mol. Res. 7: 326-335.

Benavente R and Wettstein R (1980). Ultrastructural characterization of the sex chromosomes during spermatogenesis of spiders having holocentric chromosomes and a long diffuse stage. Chromosoma 77: 69-81.

Bressa MJ, Fumigalli E, Ituarte S, Frassa MV, et al. (2002). Meiotic studies in Dysdercus Guérin Méneville, 1831 (Heteroptera: Pyrrhocoridae). II. Evidence on variations of the diffuse stage between wild and laboratory-inbred populations of Dysdercus chaquensis Freiberg, 1948. Hereditas 137: 125-131.

Bressa MJ, Papeschi AG, Fumagalli E, van Doesburg PH, et al. (2003). Cytogenetic and nucleolar meiotic cycle analyses in Dysdercus imitator Blote, 1931 (Pyrrhocoridae, Heteroptera) from Argentina. Folia Biol. 51: 135-141.

Bressa MJ, Larramendy ML and Papeschi AG (2005). Heterochromatin characterization in five species of Heteroptera. Genetica 124: 307-317.

Camacho JPM, Belda J and Cabrero J (1985). Meiotic behaviour of the holocentric chromosomes of Nezara viridula (Insecta, Heteroptera) analysed by C-banding and silver impregnation. Genome 27: 491-497.

Cattani MV and Papeschi AG (2004). Nucleolus organizing regions and semi-persistent nucleolus during meiosis in Spartocera fusca (Thunberg) (Coreidae, Heteroptera). Hereditas 140: 105-111.

Cattani MV, Greizerstein EJ and Papeschi AG (2004). Male meiotic behaviour and nucleolus organizer regions in Camptischium clavipes (Fabr.) (Coreidae, Heteroptera) analyzed by fluorescent banding and in situ hibridization. Caryologia 57: 263-273.

Colombo P and Bidau C (1985). Estudios cromosómicos en Heterópteros argentinos. I. Los cromosomas meióticos de cinco especies de Coreidae. Physis Secc. C 43: 29-40.

Di Iorio O (2004). Hemiptera: Pentatomidae. In: Catalogo de Insectos Fitófagos de la Argentina y sus Plantas Asociadas. (Cordo HA, Logarzo G, Braun K and Di Iorio O, eds.). 1st edn. Sociedad Entomologica Argentina Ediciones, Buenos Aires, 258-275.

Guerra M (1999). Hematoxylin: a simple, multiple-use dye for chromosome analysis. Genet. Mol. Biol. 22: 77-80.

González-García JM, Antonio C, Suja JA and Rufas JS (1996). Meiosis in holocentric chromosomes: kinetic activity is randomly restricted to the chromatid ends of sex univalents in Graphosoma italicum (Heteroptera). Chromosome Res. 4: 124-132.

Henderson SA (1964). RNA synthesis during male meiosis and spermiogenesis. Chromosoma 15: 345-366.

Jacobs DH and Liebenberg H (2001). Cytogenetics of Adamanotus uncotibialis Jacobs (Heteroptera: Aradidae). Caryologia 54: 83-86.

Kerzhner IM, Kuznetsova VG and Rider DA (2004). Karyotypes of Pentatomoidea additional to published by Ueshima, 1979 (Heteroptera). Zoosyst. Rossica 13: 17-21.

Klásterská I (1977). The concept of the prophase of meiosis. Hereditas 86: 205-210.

Lanzone C and Souza MJ (2006). Chromosome complement and meiosis in three species of the Neotropical bug genus Antiteuchus (Heteroptera, Pentatomidae, Discocephalinae). Genet. Mol. Biol. 29: 49-55.

Manna GK (1984). Chromosomes in Evolution in Heteroptera. In: Chromosomes in Evolution of Eukaryotic Groups (Sharma AK and Sharma A, eds.). CRC Press, Boca Raton, 189-225.

Mola LM and Papeschi AG (1993). Meiotic studies in Largus rufipennis (Castelnau) (Largidae, Heteroptera): frequency and behaviour of ring bivalents, univalents and B chromosomes. Heredity 71: 33-40.

Mola LM and Papeschi AG (2006). Holokinetic chromosomes at a glance. J. Basic Appl. Genet. 17: 17-33.

Morielle-Souza A and Azeredo-Oliveira MT (2007). Differential characterization of holocentric chromosomes in triatomines (Heteroptera, Triatominae) using different staining techniques and fluorescent in situ hybridization. Genet. Mol. Res. 6: 713-720. 
Papeschi AG and Bidau CJ (1985). Chromosome complement and male meiosis in four species of Belostoma Latreille (Heteroptera-Belostomatidae). Rev. Bras. Genet. VIII: 249-261.

Papeschi AG and Bressa MJ (2006). Evolutionary cytogenetics in Heteroptera. J. Biol. Res. 5: 3-21.

Papeschi AG, Mola LM, Bressa MJ, Greizerstein EJ, et al. (2003). Behaviour of ring bivalents in holokinetic systems: alternative sites of spindle attachment in Pachylis argentinus and Nezara viridula (Heteroptera). Chromosome Res. 11: 725-733.

Poggio MG, Bressa MJ and Papeschi AG (2007). Karyotype evolution in Reduviidae (Insecta: Heteroptera) with special reference to Stenopodainae and Harpactorinae. Comp. Cytogenet. 1: 159-168.

Rebagliati PJ (2009). Citogenética Básica, Molecular y Evolutiva en Pentatómidos de Interés Agrícola en Argentina (Pentatomidae, Heteroptera). Doctoral thesis, Facultad de Ciencias Exactas y Naturales, Universidad de Buenos Aires, Buenos Aires.

Rebagliati P, Papeschi AG, Mola LM, Pietrokovsky S, et al. (1998). Comparative meiotic studies in Triatoma sordida (Stal) and T. guasayana Wygodzinsky \& Abalos (Reduviidae, Heteroptera). Mem. Inst. Oswaldo Cruz 93: 309-315.

Rebagliati PJ, Mola LM and Papeschi AG (2001). Karyotype and meiotic behaviour of the holokinetic chromosomes of six Argentine species of Pentatomidae (Heteroptera). Caryologia 54: 339-347.

Rebagliati PJ, Papeschi AG and Mola LM (2003). Meiosis and fluorescent banding in Edessa meditabunda and E. rufomarginata (Heteroptera: Pentatomidae: Edessinae). Eur. J. Entomol. 100: 11-18.

Rebagliati PJ, Mola LM, Papeschi AG and Grazia J (2005). Cytogenetic studies in Pentatomidae (Heteroptera): a review. J. Zool. Syst. Evol. Res. 43: 199-213.

Rider DA (2008). Pentatomoidea Home Page. Available at [http://www.ndsu.nodak.edu/ndsu/rider/Pentatomoidea/]. Accessed August 20, 2009.

Schaefer WC and Panizzi AR (2000). Heteroptera of Economic Importance. 1st edn. CRC Press, Boca Raton.

Severi-Aguiar GD, Lourenco LB, Bicudo HE and Azeredo-Oliveira MT (2006). Meiosis aspects and nucleolar activity in Triatoma vitticeps (Triatominae, Heteroptera). Genetica 126: 141-151.

Solari AJ (1979). Autosomal synaptonemal complexes and sex chromosomes without axes in Triatoma infestans (Reduviidae; Hemiptera). Chromosoma 72: 225-240.

Souza HVD, Bicudo HEM, Costa LAA and Itoyama MM (2007). A study of meiosis and spermiogenesis in the testicular lobes of Antiteuchus tripterus (Heteroptera: Pentatomidae). Eur. J. Entomol. 104: 353-362.

Souza HV, Castanhole MMU, Bicudo HEM, Costa LAA, et al. (2008). Morphological patterns of the heteropycnotic chromatin and nucleolar material in meiosis and spermiogenesis of some Pentatomidae (Heteroptera). Genet. Mol. Biol. 31: 686-691.

Suja JA, del Cerro AL, Page J, Rufas JS, et al. (2000). Meiotic sister chromatid cohesion in holocentric sex chromosomes of three heteropteran species is maintained in absence of axial elements. Chromosoma 109: 35-43.

Ueshima N (1979). Hemiptera II: Heteroptera (Animal Cytogenetics, Vol. 3: Insecta, 6). Gebrüder Bornträger, Berlín.

Viera A, Page J and Rufas J (2009). Inverted meiosis: the true bugs as a model to study. Genome Dyn. 5: 137-156. (DOI: $10.1159 / 000166639)$. 